\title{
st \\ O projeto fenomenológico de fundação das ciências
}

Marcus SAGRINI

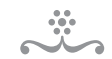

RESUMO

Em primeiro lugar, este artigo esclarece que o sentido de fundação das ciências proposto por Husserl não deve ser confundido com algum tipo de fundacionismo epistêmico (seção 1). Em seguida, expõe o primeiro modelo de fundação do conhecimento defendido por Husserl, em Filosofia da aritmética, e as principais críticas recebidas (seções 2-3). Por fim, acompanha a elaboração de um segundo modelo, apresentado em Prolegômenos à lógica pura (seções $4,-7$ ).

PalaVras-Ghave • Husserl. Fenomenologia. Fundacionismo. Elucidação filosófica. Idealidade.

\section{A Fundação FILOSÓFICA}

As ciências ocupam um lugar proeminente na obra de Husserl. Seu primeiro livro, publicado em 1891, Filosofia da aritmética, e o seu último, de 1936, A crise das ciências europeias e a fenomenologia transcendental, atestam já pelos títulos que as ciências não somente permanecem um tema constante de reflexão, mas também que a amplitude de sua consideração se alarga significativamente no decorrer da carreira do filósofo. Além disso, não seria errado discernir uma posição filosófica nuclear defendida por Husserl em relação às ciências, posição que já se esboça no livro de 1891 e que, embora assuma diferentes figuras, ainda pode ser reconhecida mesmo em seus trabalhos finais. Essa posição é aquela segundo a qual as ciências carecem de uma fundação que só pode ser oferecida pela filosofia. Neste artigo, vamos explorar duas dessas figuras, a primeira delas apresentada em Filosofia da aritmética, e a segunda em Prolegômenos à lógica pura, publicado em 1900. Antes de expor em que consiste a fundação das ciências tal como apresentadas nessas obras, cumpre desfazer alguns mal-entendidos e esclarecer aquilo que ela certamente não é.

Em algumas passagens, Husserl é bastante severo com as ciências. Nos Prolegômenos, por exemplo, ele nos apresenta a seguinte constatação: 
Mesmo o matemático, o físico e o astrônomo não necessitam, para conduzir suas operações [Lesitungen] científicas mais significativas, da visão evidente [Einsicht] dos últimos fundamentos de sua atividade, e embora os resultados obtidos possuam para eles e para outros a força de um convencimento racional, eles não podem pretender ter provado no geral as premissas últimas de suas conclusões e dos princípios sobre os quais repousa a validade de seus métodos. A isso se refere o estado de imperfeição de todas as ciências. Não mencionamos aqui a mera incompletude nas quais elas investigam as verdades de seu domínio, mas a falta de clareza interna e racionalidade, que se deve exigir independentemente da expansão da ciência $(1975, \S 4$, p. 25-6).

As ciências encontram-se, assim, em estado de imperfeição não somente porque ainda não completaram a exploração de seus respectivos domínios, mas porque falta clareza acerca de suas próprias bases e de como por meio delas o conhecimento posteriormente obtido é justificado. Segundo Husserl, mesmo na matemática, "a mais desenvolvida das ciências" (1975, §4, p. 26), os pesquisadores trabalham como "técnicos engenhosos" (1975, § 71, p. 254), os quais constroem teorias "sem ter de possuir uma visão evidente última da essência das teorias em geral" (1975, § ₹1, p. 255). E quem pode então oferecer a clareza acerca da essência das teorias científicas e de seus conceitos básicos? Este é o trabalho filosófico. Para Husserl, o filósofo não se contenta com a construção das teorias em vista da solução de certos problemas, de ordem prática ou teórica. "Se a ciência constrói teorias para o tratamento sistemático de seus problemas, o filósofo questiona qual é a essência da teoria, o que a teoria torna possível em geral etc." (1975, § 71, p. 255). A filosofia, diferentemente das ciências, vai em busca das essências e leis gerais que garantem a legitimidade última do saber. Dessa maneira, "somente a investigação filosófica complementa as operações dos cientistas naturais e matemáticos de maneira que o conhecimento teórico puro e verdadeiro se completa" (1975, § 71, p. 256).

Parece, assim, que a filosofia vai produzir um conhecimento especial que completará as ciências ao prover suas bases últimas. Husserl estaria defendendo um tipo de fundacionismo epistêmico segundo o qual o conhecimento científico seria justificado por remissão, direta ou indireta, a certos princípios ou componentes básicos imediatamente válidos, e esses princípios básicos só seriam fornecidos pela filosofia. Nessa concepção, as ciências seriam incompletas porque lhes faltam os fundamentos que garantiriam o caráter objetivo de todo o edifício do saber. O conhecimento científico, por si só, teria somente o valor de propiciar certas aplicações técnicas, mas não seria racionalmente justificado enquanto a filosofia não desvelasse tais fundamentos. 
Cabe aqui esclarecer que essa concepção de fundação não é aquela defendida por Husserl. Mesmo no final de sua carreira, o filósofo ainda lamenta que seu projeto tenha sido erroneamente associado a um tal tipo de fundacionismo. Em $A$ crise das ciências europeias, Husserl escreve:

obviamente é um erro risível mas infelizmente comum querer atacar a fenomenologia transcendental como "cartesianismo", como se seu ego cogito fosse uma premissa ou um conjunto de premissas da qual o restante do conhecimento (...) tivesse de ser deduzido, absolutamente assegurado. Não se trata de assegurar a objetividade, mas de entendê-la $(1976, \S 55$, p. 193).

É verdade que muitas vezes Husserl se inspirou na empreitada cartesiana de estabelecer um solo de evidência indubitável. Mas essa inspiração jamais alimentou a expectativa de uma invenção dos fundamentos últimos de todas as ciências. E de fato, muitos anos antes de publicar $A$ crise das ciências, Husserl já censurava Descartes por apresentar os resultados de suas Meditações metafísicas como espécies de axiomas que garantiriam a certeza de todo conhecimento científico neles baseado. No $§ 33 \mathrm{c}$ de Introdução à lógica e à teoria do conhecimento (curso ministrado durante 1906-7 e publicado postumamente), Husserl avalia o procedimento cartesiano nas Meditações metafísicas: tratava-se de suspender a validade de todo conhecimento duvidoso, de maneira a mostrar que nenhuma ciência disponível possuía um fundamento seguro, estável, o qual deveria então ser estabelecido pela reflexão filosófica. ${ }^{1}$ Para Husserl, essa tentativa de fornecer, pela reflexão filosófica, as bases interiores das próprias ciências é uma confusão inaceitável de domínios. E ao esclarecer qual é a tarefa específica da filosofia, Husserl antecipa em trinta anos aquela afirmação de $A$ crise das ciências mencionada acima: a filosofia, enquanto reflexão ou crítica (no sentido kantiano) epistemológica, "não quer teorizar. O que ela quer não se situa nos caminhos dos matemáticos ou das ciências da natureza, nem tampouco da psicologia. Ela quer 'explicitar', ela não quer nada deduzir, nada reenviar a leis como fundamentos explicativos, mas simplesmente compreender o que se situa no sentido do conhecimento e da objetividade" (1985, §33c, p. 190). A reflexão epistemológica não possui, assim, nenhum método para produzir os fundamentos internos ainda faltantes das ciências. Essas últimas não se tor-

I "E partindo desse conhecimento básico [o ego cogito], desse ponto arquimediano, eu posso então avançar de cognição para cognição, de ciência para ciência, em passos absolutamente certos que proveem uma base tão confiável para cada dúvida quanto o cogito. A totalidade do conhecimento assegurado criticamente se desenvolve então como uma matemática universal, ideal e única, uma ciência universal única de um caráter demonstrativo absolutamente ideal" (Husserl, 1985, §33c, p. 188-9). 
nam mais certas ou seguras por meio dos resultados da filosofia, as teorias provisórias não deixarão de ser provisórias, os métodos indutivos não deixarão de envolver diferentes graus de incerteza. Em suma, a validade dos conhecimentos científicos permanecerá tal como é estabelecida pelos próprios métodos científicos; a reflexão filosófica sobre o conhecimento (a tentativa de compreender o que é a objetividade por ele oferecida) em nada interfere nos fundamentos interiores a cada disciplina científica.

É preciso, assim, distinguir entre dois sentidos de fundação. Husserl reconhece, já nos Prolegômenos à lógica pura, que todas as ciências comportam métodos internos de fundação. Trata-se, nesses casos, de procedimentos lógicos que permitem conduzir de modo válido certas teses às proposições básicas de que decorrem. ${ }^{2}$ Nesse sentido, as ciências carecem de fundamentos quando apresentam conclusões lacunares, cujo laço válido com as proposições básicas não é bem demonstrado, ou mesmo quando essas últimas nem estão estabelecidas. Nesse âmbito, ao se resolver um problema de fundamento pode-se de fato tornar um certo grupo de conhecimentos mais justificado ou mais seguro. No entanto, não é esse tipo de problema que cumpre à filosofia, como investigação do conhecimento, resolver.

Ao lado da fundação interna às ciências, é preciso distinguir a fundação filosófica. Essa última não almeja sanar falhas no interior das teorias científicas ou tornar tais teorias de algum modo mais certas. Trata-se somente de investigar o que é a objetividade, isto é, de esclarecer quais são as condições que tornam possível o conhecimento objetivo, e o sentido desse último, quando obtido. Mas de que maneira se pode asseverar que essa investigação filosófica acerca do que é a objetividade complementa as ciências, tal como vimos, mais acima, Husserl sugerir? Cabe à investigação filosófica elucidar "reflexivamente as fontes subjetivas e as questões últimas sobre o sentido e a possibilidade de uma objetividade que se constrói subjetivamente" (1985, §31c, p. 163). Com essa elucidação, as ciências não vão se tornar mais ou menos certas; mas ao menos "elas se tornam de um lado a outro compreensíveis" (p. 163), no que tange a seu sentido e sua legitimidade.

Por que essa fundação filosófica das ciências é necessária? Segundo Husserl, as ciências em geral, e mesmo as disciplinas formais, tais como a matemática e a lógica, são construídas de maneira ingênua no que se refere à compreensão do sentido e da possibilidade do conhecimento objetivo: os instrumentos de pesquisa e as capacidades de reflexão são voltados para os temas objetivos que se quer conhecer, certas teses são formuladas com base em tal pesquisa e com elas se montam teorias em que o co-

2 A lógica pura, que Husserl anuncia no título de seu livro de 1900, consiste, ao menos em parte, na exposição sistemática desses métodos de fundação, exposição que os apresenta independentemente de sua aplicação em diferentes domínios materiais. 
nhecimento daqueles temas é exposto sistematicamente. Nesse modo ingênuo de proceder, "pensa-se, conhece-se, trabalha-se cientificamente sem investigar os princípios de que dependem o sentido último, o direito, a fonte de validade verdadeiramente objetiva" (1985, §31d, p. 164). Trata-se aqui daquilo que Husserl chama de orientação ou atitude natural do pensamento nas investigações científicas. Nessa orientação, o sentido e a possibilidade do conhecimento objetivo são, sem dúvida, temas pressupostos pelas investigações científicas, mas não tematizados explicitamente. Não se segue daí, obviamente, que as ciências não produzam conhecimento objetivo justificado. O conhecimento é produzido, porém, naturalmente, isto é, sem que os princípios segundo os quais essa produção ocorre sejam investigados a fundo. A proposta de Husserl é justamente realizar uma crítica do conhecimento, uma investigação reflexiva de certas condições necessárias (aquelas ligadas à subjetividade) para a efetuação do saber. Mas não que os resultados dessa investigação devam ser acrescentados ao conhecimento da atitude natural para que então ele se transforme em conhecimento objetivo ou racional. Em relação à atitude natural, Husserl reconhece que aí o conhecimento pode ser produzido sem que se conheçam os próprios princípios epistêmicos segundo os quais essa produção ocorre.

Em contraste com essa orientação ingênua, a investigação filosófica se apresenta como "uma orientação de pensamento totalmente antinatural" (1985, §31d, p. 165). A antinaturalidade da filosofia deriva de sua insistência em tornar aparente aquilo que as ciências ingênuas pressupõem mas não tematizam, a saber, as operações subjetivas pelas quais a objetividade é alcançada. Na atitude natural, o fato de que essas operações podem ser realizadas de modo bem sucedido já é suficiente; foca-se então nos resultados de tais operações, as quais, nelas mesmas, não são questionadas. Não é assim para a investigação filosófica, que quer justamente clarificar como é possível a relação entre a subjetividade e aquilo que por ela é visado como objetivo. É somente desse ponto de vista filosófico que a possibilidade da relação entre consciência subjetiva e polo objetivo (e, por conseguinte, a produção do conhecimento) aparece como problemática, e as ciências, como carentes de uma fundação acerca do sentido da própria atividade epistêmica que se concretiza na obtenção de tais conhecimentos. A fundação filosófica não é, assim, a produção de teses acrescentadas ao conteúdo das teorias científicas ou a descoberta de dados que assegurarão a certeza das teorias em vigor. Trata-se da elucidação das estruturas subjetivas que tornam possível o estabelecimento desse saber. 


\section{O PROBLEMA DA ORIGEM SUBJETIVA DO GONHEGIMENTO}

Vimos, em linhas gerais, qual é o projeto geral de fundação das ciências tal como proposto por Husserl. Mas falta ainda examinar com mais detalhe como exatamente esse projeto se realiza. A ideia principal de Husserl é que para compreender o sentido e a possibilidade do conhecimento objetivo é necessário um retorno à "origem fenomenológica" (1975, §67, p. 24,6), quer dizer, é necessário mostrar como ao menos as categorias básicas sobre os quais o conhecimento objetivo é construído podem se doar com evidência à subjetividade. Vimos que na atitude natural o conhecimento é produzido sem a preocupação de entender os princípios que o tornam possível. Entre esses princípios estão as capacidades subjetivas de apreender os temas da evidência ou de atribuir sentido a um conjunto de dados, de extrair regras gerais de alguns casos etc. A tarefa da filosofia, que para Husserl se desenvolverá justamente como uma fenomenologia, é investigar as estruturas subjetivas que condicionam o estabelecimento do conhecimento objetivo.

A fenomenologia realiza um trabalho de elucidação das fontes subjetivas que atribuem legitimidade ao conhecimento objetivo. Essa tarefa só foi formulada de maneira clara por Husserl nos Prolegômenos, com a exposição do método fenomenológico, embora já tivesse sido esboçada desde seus primeiros textos. Vamos acompanhar, no restante deste artigo, a lenta maturação dessa ideia de explicitação das fontes subjetivas do saber nos textos iniciais de Husserl até a formulação do projeto dos Prolegômenos à lógica pura, no qual se apresentam os temas da lógica como um conjunto de idealidades autônomas, cuja relação com a subjetividade (considerada em seus aspectos puros, independentes das circunstâncias empíricas) cabe justamente à fenomenologia investigar.

\section{UMA FUNDAÇÃO PSICOLÓGICA DA MATEMÁTICA}

Já em 1891, em Filosofia da aritmética, Husserl oferecia uma reflexão epistemológica acerca do conhecimento (no caso, matemático), porém sem ainda distinguir plenamente essa reflexão de uma pesquisa meramente psicológica. Em todo caso, nesse livro, Husserl já antecipa a divisão do trabalho entre matemáticos e filósofos exposta nos Prolegômenos. $\mathrm{O}$ matemático trabalha com as teorias já formalizadas e não se questiona sobre a origem dos conceitos mais básicos de sua prática. ${ }^{3}$ Por sua vez, Husserl pretende fornecer "uma caracterização psicológica dos fenômenos sobre os quais re-

3 "De onde provêm os números, em quais tarefas eles se aplicam e sob quais pressupostos - nada disso tem a ver com a aritmética" (Husserl, 1970a, p. 149). 
pousa a abstração do conceito de quantidade" (1970a, p. 20-1), entre outros conceitos básicos da matemática. De maneira geral, Husserl almeja elucidar "a origem dos conceitos de quantidade e de número" (1970a, p. 22) nos atos psíquicos correspondentes que os fundam. Assim, em relação à aritmética, Husserl esboça um quadro geral acerca do trabalho da filosofia em relação às disciplinas científicas. Trata-se de reconhecer inicialmente que "nenhum conceito pode ser pensado sem fundação sobre uma intuição concreta" (1970a, p. 79). Husserl se refere especificamente aos conceitos primitivos das disciplinas matemáticas, os quais resultariam de certos processos abstrativos sobre intuições concretas, de maneira que as características conceituais corresponderiam a determinados momentos isoláveis nessas intuições. A elucidação filosófica desses conceitos primitivos deve "indicar os fenômenos concretos a partir dos quais ou por meio dos quais eles são abstraídos, e esclarecer a gênese desse processo abstrativo" (1970a, p. 119). Desse modo, explicitam-se "os processos psíquicos que são exigidos para construir o conceito" (p. 199). Por conseguinte, no contexto da Filosofia da aritmética, a elucidação filosófica deve expor as capacidades psíquicas que, com base em intuições concretas, constituem conceitos aritméticos primitivos ao extrair por abstração certas características dessas intuições.

Em sua famosa recensão crítica de Filosofia da aritmética, publicada originalmente em 1894, no periódico Zeitschrift fur Philosophie und philosophische Kritik, Frege nota que Husserl acaba por se comprometer com consequências psicologistas. Ao buscar a origem dos conceitos aritméticos em operações psíquicas, Husserl teria se limitado a tratar desses conceitos como conteúdos de vivências subjetivas, como representações. Husserl falharia, assim, em expor o caráter puramente objetivo desses conceitos e só os consideraria enquanto temas dependentes dos atos subjetivos; por conseguinte, as análises de Filosofia da aritmética seriam análises psicologistas. 4 É bastante provável que a recensão de Frege tenha repercutido no trabalho de Husserl, de maneira a despertar esse último para o caráter autonomamente objetivo dos conceitos matemáti$\cos ^{5}$ Mas essa repercussão não motivou o abandono do projeto do livro de 1891 , e sim

4. “É uma pena que o autor [Husserl] não tenha distinguido claramente entre 'A' e 'representação de A'. Mas se minha representação de número não é o próprio número então o modo de consideração psicológico perde o chão, enquanto almeja investigar a essência dos números. (...) Faz uma enorme diferença ao modo de investigação se a representação número é ela própria o objeto da investigação ou se é meramente uma representação do objeto real. (...) Se um geógrafo chegar a ler um livro sobre oceanografia em que a origem dos mares fosse explicada psicologicamente, ele indubitavelmente ficaria com a impressão de que o verdadeiro ponto em questão foi perdido de um modo estranho. Eu tenho a mesma impressão do presente livro. Certamente o mar é algo real, e o número não é; mas isso não o impede de ser objetivo, e isso é o que importa" (Frege, 1967, p. 192).

5 O próprio Husserl reconhece que paulatinamente se aproximou ao menos do caráter antipsicologista da posição geral assumida por Frege. Numa nota nos Prolegômenos, afirma: "eu não defendo mais a crítica de princípio que eu fiz à posição antipsicologista de Frege em minha Filosofia da aritmética” (Husserl, 1975, § 45, p. 172). 
a sua lenta correção de modo a afastá-lo do psicologismo. Em suma, Husserl não descarta o problema de como os objetos lógicos e matemáticos se relacionam com a subjetividade, embora passe a buscar uma fórmula não-psicologista dessa relação.

A importância desse problema já é confirmada por Husserl numa recensão de um livro de Schröder, publicada no mesmo ano em que lançou Filosofia da aritmética, 1891. Nessa recensão, Husserl lamenta que esse autor reduza a lógica à mera extração de consequências, e não considere as capacidades mentais [Geistesbetätigungen] que estão na base das deduções como tema da lógica. ${ }^{6}$ A consideração de tais capacidades seria indispensável para compreender em toda a sua amplitude as especificidades da lógica. Parece-nos que no decorrer da década Husserl se esforça por desenvolver uma análise cada vez menos psicologizante dessas capacidades subjetivas ligadas à lógica. A lenta maturação dessa análise se dá por duas vias reflexivas, as quais se unirão na doutrina exposta nos Prolegômenos, em 1900. Acompanhemos o desenrolar dessas duas vias.

\section{Esboço DA TEORIA DA INTENGIONALIDADE}

Em 1893-4, Husserl escreve dois textos do que chamaremos aqui de primeira via. Trata-se de artigos que esboçam sua doutrina da intencionalidade. No artigo Estudos psicológicos para a lógica elementar, escrito em 1893 e publicado no ano seguinte, Husserl investiga a diferença entre intuição sensível e representação no sentido de tomar algo presente como um substituto (símbolo) de algo ausente. A diferença entre ambas não é de conteúdo vivido, mas sim uma diferença “de 'modo de consciência' (do estado de espírito, da participação psíquica)" (1979a, p. 134), tal como afirma Husserl no texto de apresentação desse artigo, de 1897. Uma mesma sequência de rabiscos pode ser apreendida somente em seu caráter sensível ou, se se trata de letras de um alfabeto, como um símbolo, uma palavra. O mesmo conteúdo comporta assim diferentes modos de visada subjetiva. No primeiro caso, trata-se de intuição, um tipo de vivência que contém em si mesma, como conteúdo imediatamente dado, o seu objeto. ${ }^{7}$ No segundo caso, trata-se de representação, uma vivência "que não encerra em si seus objetos como imanentes (...), mas que meramente os intenciona" (Husserl, 1979d, p. 107). Por visar ou intencionar, Husserl entende “dirigir-se por meio de não importa quais conteúdos

\footnotetext{
6 "A teoria de todas essas atividades mentais que, ainda que não sejam atividades de consequência, servem para a dedução de verdades científicas, pertence manifestamente à lógica dedutiva” (Husserl, 1979b, p. 7).

${ }_{7}$ Trata-se de "vivências psíquicas (...) que não meramente visam seus 'objetos', mas que os apreendem verdadeiramente em si como conteúdo imanente" (Husserl, 1979d, p. 108).
} 
dados à consciência para outros conteúdos que não são dados (...), utilizar com compreensão [mit Verständnis] os primeiros como representantes dos segundos” (p. 10ך). Aqui, a intencionalidade é associada ao caráter de mediação de certas vivências psíquicas que apresentam indiretamente algo.

Esse caráter é desenvolvido por Husserl no segundo texto que gostaríamos de analisar, Objetos intencionais, de 1894. Ali, limitando-se às vivências de expressão linguística dos nomes (e, por extensão, das proposições), Husserl considera haver um "conteúdo de representação" (Husserl, 1979c, p. 3०3) pertencente a cada ato de representação. Esse conteúdo é a significação linguística, responsável pela referência objetiva a algo. É por meio dela que se realiza a mediação entre um nome e algo nomeado, por exemplo. ${ }^{\mathbf{8}}$ E a significação pode ser considerada de maneira objetiva, isto é, como um conteúdo idêntico passível de representação por diversos sujeitos em diferentes circunstâncias espaço-temporais. As vivências de expressão linguística são assim constituídas de tal modo que elas comportam significações objetivas. Husserl abre aqui a possibilidade de descrever as vivências subjetivas de expressão de uma maneira não psicológica. Trata-se, nesse caso, de analisar não as particularidades psicológicas ligadas às enunciações, mas o "conteúdo ideal dos atos de representação" (1979c, p. 311), ou seja, a "identidade da intenção" (p. 311) de representar algo por meio de significações objetivamente partilháveis. A estrutura da vivência de representação linguística envolve, assim, componentes ideais, o que faculta uma análise não psicologista do ato de significação. Husserl se aproxima aqui de uma investigação das capacidades subjetivas tomadas de modo independente de todo contato com o empírico, a qual será plenamente exposta nos Prolegômenos. No entanto, ainda estamos longe da posição assumida nesse livro no que tange ao estatuto ideal dos objetos lógico-matemáticos.

\subsection{O ESTATUTO ONTOLóGico dos OBJETOS LóGico-MATEMÁticos}

Em Objetos intencionais, Husserl atribui idealidade ao conteúdo de significação do ato de representar, mas ainda não assume a autonomia do ser ideal dos objetos lógicomatemáticos, o que é um tema fundamental dos Prolegômenos. Segundo Objetos intencionais, os atos de representação possuem um conteúdo objetivo, a saber, "a representação no sentido objetivo em tais e tais conexões objetivas" (1979c, p. 314), quer dizer, significações idênticas por meio das quais se determina o conteúdo representativo dos

8 “A significação é a única determinação interna essencial da representação, enquanto a relação objetiva reenvia a certas conexões de verdade, e, por conseguinte, de juízo, no interior das quais a significação se articula” (Husserl, 1979c, p. 336). 
atos. Esse caráter uno da significação atribui um valor objetivo aos juízos realizados por meio dela, e isso independentemente da questão de saber se tais juízos se referem verdadeiramente a objetos ou não. ${ }^{9}$ No entanto, uma vez que, normalmente, por meio dos juízos os sujeitos almejam tratar diretamente dos objetos julgados, há então uma tendência a atribuir o valor objetivo dos juízos para os objetos visados. Por conseguinte, seria necessário que todo juízo ou representação se referisse realmente a algum objeto para adquirir objetividade. Mas isso é patentemente falso, conforme o caso dos absurdos lógicos (tais quais "quadrado redondo") facilmente confirma. Não há nenhum objeto verdadeiramente referido nos casos desses absurdos, e mesmo assim há um conteúdo idêntico (reconhecível em diversos juízos) referente a sua representação. E de nada adiante supor que haveria um tipo especial de objeto nesses casos de absurdos, aquilo que Twardowski (contra quem Husserl escreveu esse texto em questão) chamava de "objetos intencionais" por oposição a objetos reais e verdadeiros. Trata-se de uma distinção que duplica desnecessariamente o conceito de "objeto", como se, além da existência de objetos verdadeiros houvesse ainda um outro tipo de existência, aquela meramente intencional. ${ }^{10}$ Para Husserl, a dificuldade advinda dos absurdos não implica uma distinção do estatuto ontológico dos objetos, mas somente uma mera diferenciação dos juízos. A questão se resolve "em uma simples divisão das representações em representações A, que se articulam em juízos válidos de existência da forma 'A existe', e, por sua vez, em [representações] B, que se articulam em juízos válidos de existência da forma correlativa "B não existe" (1979c, p. 314). Assim, certos conteúdos de representação se articulam com juízos existenciais positivos, enquanto outros não, sem que esses últimos percam seu caráter objetivo, o qual não deriva de uma correspondência efetiva a um objeto, mas do conteúdo de significação.

Nem todas as representações que não se articulam a juízos existenciais positivos revelam a ausência de objeto correspondente de maneira tão clara quanto os absurdos lógicos. Em certos casos, por meio da assunção hipotética de um contexto geral (com entidades determinadas e regras de interação entre elas), pode-se atribuir uma existência condicionada aos objetos referidos pelas representações. É o que ocorre, por exemplo, na mitologia e nas artes literárias em geral: "nós dizemos que "na mitologia grega' há ninfas, 'no conto popular alemão', há um chapeuzinho vermelho, etc." (1979c, p. 328), exemplifica Husserl. Além disso, de um modo que não deixa de surpreender os

9 "O juízo sobre o objeto representado é, segundo seu valor objetivo, um juízo sobre as representações, e [isso] que sobre elas é enunciado é o fato de que elas têm a mesma intenção objetiva, uma mesma propriedade do conteúdo, que se chama precisamente representar ou visar um objeto" (Husserl, 1979c, p. 317-8).

10 Para Husserl, essa duplicação é inaceitável: “as expressões 'um objeto’ e "um objeto existente, verdadeiro, efetivo e próprio' são completamente equivalentes” (1979c, p. 315). Não há sentido em supor “objetos intencionais” diferentes dos objetos verdadeiros. 
leitores dos Prolegômenos, Husserl atribui um caráter hipotético semelhante a todo juízo existencial realizado no âmbito da matemática. O sistema geométrico, por exemplo, se baseia em definições axiomáticas daquilo que é o espaço, daquilo que são pontos, intersecções etc. As proposições existenciais da geometria ("existem tais e tais figuras”, e.g.) supõem essas definições e são condicionadas a sua aceitação. Dessa maneira, "a existência e a não existência matemáticas são então uma existência e uma não existência que se localizam sob a posição hipotética das bases que lhes são relativas" (p. 328). As proposições existenciais matemáticas são consequências da assunção hipotética das definições axiomáticas. E por sua vez, os axiomas que delimitam o contexto global das teorias matemáticas "não são existência sob hipótese, mas hipóteses, portanto, existências novamente impróprias" (p. 328). Quer dizer que tanto no nível das consequências quanto dos fundamentos axiomáticos não há existência objetiva incondicionada: as consequências são condicionadas hipoteticamente pelos axiomas, e esses são, em si mesmos, meras hipóteses e não a posição de objetos verdadeiros.

Vemos, assim, que em 1894. Husserl ainda não admitia a autonomia objetiva dos temas ligados à matemática formal. Sem dúvida ele já reconhece a possibilidade de abordar a estrutura das vivências subjetivas de modo objetivo-ideal, independentemente das particularidades psicológicas, mas essa objetividade ainda não é estendida à matemática e à lógica, extensão que ocorrerá nos Prolegômenos. Falta ainda a Husserl, para se aproximar da posição aí assumida, reconhecer que o caráter existencial das proposições matemáticas não decorre de um condicionamento hipotético, mas de seu serideal. Falta, assim, ampliar a noção de ser de maneira a incluir a idealidade como um gradiente ontológico irredutível. Em Objetos intencionais, Husserl defende que "não há modos diferentes de existência e de validade" (1979c, p. 326); não há, dessa maneira, o ser ideal ao lado do real, mas somente assunções hipotéticas de diversos domínios de existência, os quais não possuem a mesma objetividade que o mundo real. "Só há uma verdade e um mundo" (1979c, p. 329), insiste Husserl, de modo que as representações religiosas, míticas e mesmo matemáticas não possuem o teor ontológico daquelas que se referem à realidade sensível. Se normalmente os juízos referentes a essas representações parecem veicular verdadeiramente uma posição de existência, isso decorre, crê Husserl em 1894, somente de "razões de comodidade prática" (p. 329), conforme as quais é menos laborioso se servir dessas representações de maneira incondicionada do que a cada vez remetê-las ao contexto que as condiciona. Porém, do ponto de vista lógico, a expressão correta dos juízos associados a tais representações exige a forma hipotética, o que torna explícito, ao menos nesse âmbito, que os objetos lógico-matemáticos não são objetos verdadeiros, mas ficções condicionadas à aceitação hipotética dos contextos axiomáticos de base. 


\section{A OBJETIVIdAdE DA LóGica}

Nessa primeira via de reflexão, Husserl estabelece as bases para uma análise pura das capacidades subjetivas. Por sua vez, em textos que comporiam uma segunda via reflexiva, Husserl constrói paulatinamente a concepção da lógica e da matemática como disciplinas objetivas autônomas. No último capítulo de Filosofia da aritmética, Husserl questiona pelas origens lógicas da aritmética, entendida como um sistema de operações sobre signos (representações indiretas ou impróprias de conceitos). Para ele, "o método dos signos sensíveis é o método lógico da aritmética" (1970a, p. 257), que se origina das severas limitações humanas de representar direta ou propriamente os conceitos numéricos. ${ }^{11}$ Portanto, explorar as bases lógicas da aritmética significa desenvolver "uma lógica dos métodos simbólicos do conhecimento" (p. 257). Nesse sentido, a lógica é apresentada como disciplina que investiga os encadeamentos simbólicos e suas regras. Trata-se de um estudo geral das operações propiciadas pelos signos e do modo como elas permitem o acréscimo do conhecimento. Há um caráter eminentemente prático nessa concepção de lógica, já que ela é concebida como uma tecnologia geral, isto é, como um conjunto de expedientes técnicos que permitem fixar regras para a obtenção segura de conhecimentos com base na concatenação de símbolos. Essa concepção já era apresentada por Husserl no texto Sobre a lógica dos signos (semiótica), de 1890 , no qual a lógica é definida como um conjunto de métodos que extraem, das inferências em linguagem natural, algoritmos formais que garantem a correção dos juízos pautados pela sequência de passos ali fixada com exatidão. ${ }^{12}$

Na recensão a um livro de Schröder, de 1891, Husserl começa a alterar sua concepção de lógica. Schröder defende que as inferências lógicas realizadas em linguagem natural são plenamente redutíveis ao cálculo lógico de extração de consequências baseado em certos algoritmos gerais. ${ }^{\mathbf{1 3}}$ Trata-se de uma concepção semelhante àquela defendida por Husserl no final de Filosofia de aritmética, mas que agora será duramente criticada. Conforme mencionamos acima, Husserl admite sem problemas que há

11 Segundo Husserl, “somente em circunstâncias particularmente favoráveis podemos ainda nos representar de uma maneira própria quantidades concretas de aproximadamente uma dúzia de elementos, quer dizer, apreender efetivamente (...) cada um dos seus membros ao mesmo tempo que todos os outros, como algo de observado por si. Por conseguinte, a dúzia (ou um número inferior que lhe seja próximo) é o limite último para formar os conceitos de números próprios" (1970a, p. 192).

12 "Uma lógica formal verdadeiramente fecunda se constitui primeiramente como uma lógica dos signos, a qual, quando suficientemente desenvolvida, formará uma das partes mais importantes da lógica em geral (enquanto arte do conhecimento). A tarefa da lógica é aqui a mesma que alhures: dominar os procedimentos naturais do espírito que julga, examiná-los, fazer compreender o valor que eles têm para o conhecimento, para poder finalmente determinar com exatidão seus limites, sua extensão, seu alcance, e estabelecer relativamente a isso regras gerais" (Husserl, 197ob, p. $\left.37^{3}\right)$.

13 Para um exame detalhado das posições de Schröder e das críticas formuladas por Husserl, cf. Brisart, 1999. 
capacidades mentais responsáveis pela extração de consequências dedutivas, e, além disso, sugere que o estudo de tais capacidades deveria ser tema da lógica. No entanto, ele rejeita que o cálculo lógico constitua a teoria lógica das inferências realizadas por tais capacidades naturais. Afinal, para Husserl, o cálculo é a aplicação de um algoritmo que, por meio de signos, substitui as deduções em linguagem natural. O cálculo não é uma dedução, mas somente um procedimento técnico que, tal como bem nos lembra Brisart, "nos economiza o trabalho de realizá-la” (1999, p. 26). As regras do cálculo lógico não são as leis gerais da dedução, mas somente orientações práticas para aplicar corretamente algum algoritmo em questão. O cálculo não esgota assim a complexidade da lógica, mas apenas substitui certos padrões de dedução natural por procedimentos simbólicos fixos; o cálculo nada esclarece acerca das leis puramente lógicas e nem da sua relação com a subjetividade cognoscente. ${ }^{\mathbf{1 4}}$

Na recensão a Schröder, conforme vemos, Husserl não mais identifica a lógica a uma técnica algorítmica para conversão de inferências naturais. Desde então, abre-se a possibilidade de considerá-la como uma disciplina teórica autônoma, possibilidade que Husserl desenvolve efetivamente no curso Lógica, ministrado em 1896. Nesse curso, publicado postumamente, Husserl apresenta a ideia de tomar a lógica como uma "doutrina da ciência" (2001, p. 15), quer dizer, como uma investigação dos métodos e estruturas formais responsáveis pela obtenção de conhecimento em quaisquer ciências. O conhecimento científico é obtido e exposto de forma sistemática, e essa sistematicidade teórica pode ser investigada em seu caráter geral. Husserl crê ser possível distinguir formas de conexão teórica e de obtenção de verdade "típicas" (2001, p. 16), quer dizer, reconhecíveis nos mais diversos âmbitos do conhecimento, independentemente de suas particularidades materiais. Se não houvesse essa independência, argumenta Husserl, "haveria somente lógicas dispostas uma ao lado da outra, mas nenhuma lógica geral" (2001, p. 17). No entanto, é possível desenvolver uma "lógica pura" (2001, p. 19), dedicada ao estudo das formas de encadeamento teórico válidas para quaisquer ciências. E para o desenvolvimento dessa disciplina, é imprescindível distinguir entre "a representação ou visada [Meinen] de uma proposição e a própria proposição" (p. 19). Husserl parece aqui responder diretamente às críticas de Frege: a lógica não deve investigar as representações psíquicas pelas quais os objetos lógicos são apresentados, mas deve se voltar para esses próprios objetos, os quais se revelam como um "idêntico, o qual não é um fenômeno individual" (p. 19).

14 "O cálculo lógico é então um cálculo de puras consequências, mas não é sua lógica. Ele não o é, assim como a arithmetica universalis, que envolve o domínio dos números em seu conjunto, não oferece uma lógica desse domínio. Sobre os processos mentais que deduzem, nós não aprendemos mais num caso que no outro. Por conseguinte as 'leis' do cálculo não são absolutamente as normas de todo 'pensamento consequente' ou, mais exatamente, de toda dedução de consequências segundo puras relações de condicionalidade” (Husserl, 1979b, p. 8). 


\section{Os objetos Lógicos E A SUBJETIVIDADE COMo IDEALIDADES}

Já em 1896 Husserl esboça a ideia da lógica como uma doutrina geral acerca do caráter teórico das ciências em geral. Além disso, já assume de maneira clara o caráter objetivo-ideal dos temas lógicos em oposição às particularidades psíquicas dos atos que os visam. ${ }^{15}$ Alguns anos mais tarde, nos Prolegômenos, Husserl reúne as duas vias de reflexão elaboradas até então. Ali não só é defendida a objetividade ideal dos conceitos, proposições e leis da lógica e da matemática formal, mas também se investigam as estruturas subjetivas que podem corresponder a tal objetividade, de maneira a elevar as reflexões sobre a intencionalidade psíquica a um novo patamar, aquele da idealidade. À concepção puramente ideal da lógica corresponde uma análise da subjetividade em termos de suas estruturas ideais. Daí por exemplo o exame da capacidade subjetiva de ideação, quer dizer, de apreensão evidente dos objetos e conceitos gerais lógico-matemáticos. Essa capacidade estava completamente ausente das exposições das atividades intencionais contidas nos artigos de 1893-4, examinados há pouco. Uma vez que ali, principalmente no texto Objetos intencionais, as teorias matemáticas são tratadas como ficções úteis condicionadas hipoteticamente, não havia necessidade de se supor uma tal capacidade de apreensão direta das idealidades. Porém, após reconhecer o caráter ideal da lógica, Husserl passa a investigar qual capacidade subjetiva daria acesso a esse domínio objetivo. ${ }^{\mathbf{1 6}}$ E essa investigação busca revelar as estruturas intencionais da subjetividade não como particularidades psíquicas de seres reais, mas como estruturas puras, em correlação com o conhecimento objetivo em geral.

\section{UMA FUNDAÇÃO NÃO-PSIGOLOGISTA DAS GIÊNGIAS}

Essa consideração das estruturas intencionais em seu nível puro implica uma reformulação da tarefa de elucidação filosófica tal como esboçada pela Filosofia da aritmética. Vimos que, nesse livro, tratava-se de remeter os conceitos primitivos das disciplinas aritméticas às intuições concretas com base nas quais eles seriam abstraídos. Não é esse o caso nos Prolegômenos: ainda que Husserl reconheça que a ideação, ou seja, a apreensão evidente das espécies categoriais, toma como apoio uma intuição concreta ou sensível, ele rejeita que o caráter objetivo dos conceitos e leis lógicas (o caráter universalmente idêntico, que é instanciado em inúmeros casos particulares) se origine da

15 "O fundamento primeiro e principal de toda lógica é a teoria objetiva, isto é, não-psicológica, das relações de condicionalidade entre as proposições" (Husserl, 2001, p. 23).

16 Nota-se assim que são os domínios objetivos que servem de fio condutor para a reflexão fenomenológica. 
intuição concreta (cf. 1975, § 24, p. 86). Não há sentido em buscar nos fenômenos concretos as características objetivo-ideais das quais os conceitos e leis a priori da lógica pura se originam, já que justamente eles são a priori e não são de modo algum gerados por meio de tais fenômenos, ainda que esses possam servir de apoio para a ideação. ${ }^{\mathbf{1 7}}$ Desde então, o sentido de elucidação filosófica nos Prolegômenos é outro: trata-se de levar as construções objetivas da lógica pura à intuição, mas não à intuição concreta de singularidades reais, e sim à intuição evidente, a qual, na fenomenologia de Husserl, é uma estrutura subjetiva que não se limita à percepção sensível, mas que também ocorre na doação das puras idealidades. Essa é a origem fenomenológica (cf. 1975, § 67) que se trata de investigar: o modo intencional por meio do qual as objetividades lógicas são apreendidas com evidência. É preciso distingui-la da origem psicológica, ou seja, da produção efetiva de algo por atos psíquicos. Parece que Husserl não havia distinguido perfeitamente entre esses dois tipos de origem em Filosofia da aritmética, o que ali ainda o comprometia com o psicologismo, como notou Frege. Somente ao atribuir o estatuto de idealidades aos temas lógicos, e ao considerar as estruturas subjetivas em correlação com tais temas também como estruturas ideais, é que Husserl pôde escapar das censuras recebidas de tal autor.

A descrição dessas estruturas subjetivas é a primeira tarefa fenomenológica formulada por Husserl em toda a sua obra. O termo "fenomenologia", embora presente nas reflexões de vários autores do período, ${ }^{\mathbf{1}}$ foi fixado de uma maneira inconfundível (tornando-se o nome de um método e de uma doutrina em particular) somente com Husserl. E a primeira vez que o termo aparece em sua obra publicada é nos Prolegômenos à lógica pura. Para ser mais preciso, na primeira edição desse texto, o termo só aparece uma única vez, numa nota em que Husserl demarca a especificidade da sua investigação ao excluir do campo da psicologia "a fenomenologia descritiva da experiência interna" (1975, §57, p. 215, nota). Na segunda edição, Husserl reformula esse trecho de modo a marcar sua posição de modo ainda mais claro: "eu estabeleço uma distinção profunda entre a psicologia empírica e a fenomenologia que lhe serve de fundamento (assim como essa funda, de uma outra maneira, a crítica do conhecimento)" (p. 215, nota). Em seguida, Husserl explica o sentido desse novo tipo de investigação: "entendo por fenomenologia uma doutrina pura eidética [reine Wesenslehre] das experiências vividas" (p. 215, nota). Cabe à fenomenologia descrever as experiências vividas, mas não como experiências factuais desenroladas causalmente no fluxo temporal

17 Conforme nota M. Hartimo, "enquanto na Filosofia da Aritmética o lado objetivo era baseado nas apresentações [Vorstellungen] concretas, agora nos Prolegômenos o lado objetivo é puramente ideal” (2003, p. 128).

18 H. Spiegelberg indica que, além de autores da escola hegeliana, Brentano, Mach e Hering já usavam esse termo antes de Husserl, embora com um sentido diferente (cf. Spiegelberg, 1960, p. 8, 27-8, 53). 
e sim como experiências puras, quer dizer como formas ou essências de estruturas noéticas independentes de sua realização empírica. Trata-se de discriminar essas formas, de maneira a estabelecer uma doutrina eidética, quer dizer, uma teoria a priori dos componentes de um certo domínio, no caso, do domínio da subjetividade pura. Assim, não importa à fenomenologia a diversidade psíquica empírica, mas sim as estruturas subjetivas puras, isto é, as essências intencionais que se correlacionam com as verdades objetivas. ${ }^{19}$

Fundar o conhecimento, nesse contexto, significa explicitar quais são as estruturas subjetivas (em seus caracteres eidéticos) responsáveis por apreender com evidência a objetividade ideal da lógica. E uma vez que os componentes básicos dessa objetividade formam os métodos de obtenção de conhecimento de qualquer investigação científica, a fenomenologia pode almejar uma fundação indireta de todas as ciências. Não se trata de examinar uma a uma as ciências particulares e de reenviar seus conceitos às intuições concretas fundantes, mas sim de se dirigir à própria ideia da cientificidade tal como esboçada pela lógica pura, ideia que cada ciência particular atualizará a sua maneira. É assim, ao apresentar a fenomenologia como uma elucidação da lógica pura, que Husserl estabelece, por volta de 1900, um projeto geral de fundação filosófica que escapa às censuras de psicologismo recebidas pelas teses defendidas em Filosofia da aritmética.\$

Marcus SAGRINI

Pós-doutorando do Departamento de Filosofia, Universidade de São Paulo. Pesquisador do Projeto Temático "Gênese e significado da tecnociência", Fapesp, Brasil. sacrini@usp.br

19 “Não são fenômenos individuais, mas formas de unidades intencionais que serão analisadas" (Husserl, 1975, § 47 , p. $\left.17^{8}\right)$. 


\begin{abstract}
AB STRACT
First, this article makes it explicit that the meaning of foundation of sciences proposed by Husserl should not be mistaken for some kind of epistemical foundationalism (section 1). Next, it sets forth the first model of foundation of knowledge held by Husserl, in Philosophy of arithmetic, and the main criticisms received (sections 2-3). At last, it follows the elaboration of a second model, presented in Prolegomena to pure logic (sections 4- 7 ).
\end{abstract}

KeYwords • Husserl. Phenomenology. Foundationalism. Philosophical clarification. Ideality.

\title{
REFERÊNGIAS BIBLIOGRÁFIGAS
}

Biemel, W. (Ed.). Husserliana. Haag: Martinus Nijhoff, 1976. v. 6.

Brisart, R. Le tournant logique de Husserl em 1891. La recension de Schröder et sés antécédents.

Recherches Husserliennes, 10, p. 3-34, 1999.

Dahlstrom, D. (Org.). Husserl's logical investigations. Boston: Kluwer, 2003.

Eley, L. (Ed.). Husserliana. Haag: Martinus Nijhoff, 1970. v. 12.

Frege, G. Rezension von E. Husserl, Philosophie der arithmetik I. In: Kleine Schriften. Darmstadt:

Georg Olms, 1967. p. 179-92.

HaRtimo, M. Husserl's prolegomena: a search for the essence of logic. In: Dahlstrom, D. (Org.). Husserl's logical investigations. Boston: Kluwer, 2003. p. 123-4,6.

Holenstein, E. (Ed.). Husserliana. Haag: Martinus Nijhoff, 1975. v. 18.

Husserl, E. Philosophie der Arithmetik. Mit ergänzenden Texten (1890-1901). In: Eley, L. (Ed.).

Husserliana. Haag: Martinus Nijhoff, 1970a. v. 12, p. 5-283.

. Zur Logik der Zeichnen (Semiotik). In: Eley, L. (Ed.). Husserliana. Haag: Martinus Nijhoff, 197ob.

v. 12, p. $34,0-73$.

. Logische Untersuchungen. Erster Teil. Prolegomena zur reinen Logik. In: Holenstein, E. (Ed.).

Husserliana. Haag: Martinus Nijhoff, 1975. v. 18, p. 1-258.

. Die Krisis der europäischen Wissenschaften und die transzendentale Phänomenologie. In: BiemeL,

W. (Ed.). Husserliana. Haag: Martinus Nijhoff, 1976. v. 6, p. 1-276.

. Bericht über deutsche Schriften zur Logik aus dem Jahre 1894. In: Rang, B. (Ed.). Husserliana.

Haag: Martinus Nijhoff, 1979a. v. 22, p. 124,-51.

. Besprechung von Schröder, E. In: RANG, B. (Ed.). Husserliana. Haag: Martinus Nijhoff, 1979b. v. 22, p. 3-43.

. Intentionale Gegenstände. In: Rang, B. (Ed.). Husserliana. Haag: Martinus Nijhoff, 1979c. v. 22, p. $3 \circ 3-48$.

Psychologische Studien zur Elementaren Logik. In: RANG, B. (Ed.). Husserliana. Haag: Martinus

Nijhoff, 1979d.v. 22, p. 92-123.

. Einleitung in die Logik und Erkenntnistheorie. Vorlesungen 1906/07. In: Melle, U. (Ed.). Husserliana. Haag: Martinus Nijhoff, 1985. v. 24, p. 1-355.

. Logik. Vorlesung 1896. In: Schunmann, E. (Ed.). Husserliana Materialienbänd. Boston: Kluwer, 2001.

v. 1, p. 1-328.

Melle, U. (Ed.). Husserliana. Haag: Martinus Nijhoff, 1985, v. 24.

RANG, B. (Ed.). Husserliana. Haag: Martinus Nijhoff, 1979. v. 22.

Schunmann, E. (Ed.). Husserliana Materialienbänd. Boston: Kluwer, 2001, v. 1.

Spiegelberg, H. The phenomenological movement. An historical introduction. Haag: Martinus Nijhoff, 1960. 